DOI: https://doi.org/10.3126/njdrs.v15i0.31601

\title{
A Comparative Study of Productivity in Self-Governed and Jointly-Governed Irrigation System in Inner Terai of Nepal
}

\author{
Narayan Prasad Bhatta, PhD \\ E-mail for correspondence: nbhatta@gmail.com
}

\begin{abstract}
Government of Nepal has declared irrigation as one of the leading programs for the agriculture development. Though Nepal has abundant water resources, water available for sound irrigation is still scarce. In the absence of well-organized water governance mechanisms, adequacy, fairness and reliability of water and sustainability of operation and maintenance, crop productivity remain low. This is not properly happening as most of the farmers have inadequate irrigation, inputs, technology, low education status, subsistence oriented farming, marginal farmers, low farm income, low purchasing power and poor health. The crop cultivation more than one time in a year has its positive relationship with cropping intensity and vice versa in the study area. Hence, households need to be getting up and encouraged towards year round irrigation that produce different types of the crops in different seasons and ultimately backs up in cropping intensity as well as productivity. The crop production is fluctuated widely as a result of the amount of water available as well as weather conditions. Despite the higher yield of spring paddy, the cropped area is constrained due to limit water availability in spring season.
\end{abstract}

Key words: Governance mechanisms, irrigation, agriculture, productivity

\section{Background}

As agriculture is the backbone of the economy, the government of Nepal has declared irrigation as one of the leading programs for the agriculture development. Though Nepal has abundant water resources, water available for sound irrigation is still scarce. In the absence of well-organized water governance mechanisms, adequacy, fairness and reliability of water, and sustainability of operation and maintenance, crop productivity remain low.

The Water Users Association (WUA) cannot fulfill the required irrigation delivery if they are not properly trained, capacitated and managed. This is not properly happening as most of the farmers have inadequate irrigation, inputs, technology, low education status, subsistence oriented farming, marginal farmers, low farm income, low purchasing power and poor health. This study aims at determining the scope of improving the performance of the irrigation systems at watercourse and farm through governance structural and operational changes in the systems. The need for improvement could be established through a diagnostic analysis of the system performance. The type and nature of the interventions could be decided on the basis of an analysis of the strengths and weaknesses of the system. During the last few decades there has been a very rapid expansion of irrigation facilities all over the world (DoI, 2016). Nepal is not an exception, and it has chosen irrigation development as a vehicle for time-targeted progress. At certain year, the rate of irrigation development was the highest. Provision of 
irrigation facilities has raised agricultural production, has improved productivity and has brought some sort of stability in agricultural system. In spite of these substantial gains, there is a growing perception that the performance of irrigation system has been less than satisfactory. Smaller than expected increase in productivity, low irrigation intensities, higher than anticipated costs of operation and maintenance, and discrimination in water distribution are frequently mentioned shortcomings of irrigation system.

The scope for additional increase in area under irrigation at a reasonable cost is not very high. Also, allowing the present state of affairs to continue for long may have bearing on the long-term sustainability of irrigation system. The conviction is spreading that a major breakthrough in as irrigated agriculture is possible only through the handover irrigation systems to WUA. It is existing practices after diagnosing the causes through performance analysis (DoI, 2016). Meaningful performance review is possible only if there is a clear understanding of how we define the irrigation system, its management and the objectives for which it has been created. The vastness of the subject also makes it necessary to define the boundaries of the proposed research along with anticipated outputs and future impact. Physically, an irrigation system may include capture and storage, conveyance, bulk distribution, delivery, application and removal of water from agricultural land. This physical irrigation management is exclusively dealt by DoI and the officials of the agriculture department. Terai is the main food basket of the country. Lack of institutional arrangements, reliable an irrigation delivery service particularly in the Terai, surface irrigation offers potentially viable schemes for adequacy, fairness and reliability, and sustainable systems for water delivery services for farming. It enables farmers a better quality of living.

\section{Major Crops}

Critically, Nepal is only country in South Asia wherein the population growth rate $(2.1 \%)$ is higher than the cereal production growth rate $(1.7 \%)$. Consequently, Nepal's domestic production has not been able to fulfill demand and Nepal has been a net importer of cereals since 1980s. Overall food availability would depend on domestic production as well as on food trade, food stocks and also upon food aid. Actually agriculture is a complex profession in the sense to obtain an outcome of the efforts of farmers by transferring innovative technologies to the farm community through extension. Farmers require credit, essential input: agronomical, pathological, soil, irrigation, post-harvest and marketing knowledge should exist as preconditions for the farmers. In Nepal, economy is dominated by agriculture where cereal crops dominate the cropping pattern. Cereals are the most important and most of the Nepalese's livelihood depends on. Paddy, maize, wheat, oil seeds and legumes are the major crops and the productivity is either stagnant or slight even though previous efforts have been made to increase agricultural production. Moreover, there are wide fluctuations of production as a result of erratic droughts or flooding, and a lack of fertilizers and seeds. The availability of agricultural land to expand crop production is already beyond its carrying capacity, so the country is not in a position to meet its food demand and there is an overall food deficit.

As reported by the respondents, they cultivated spring paddy, summer paddy, wheat, maize, oil seeds and pulses as main crops. Multi-cropping system is a common phenomenon amongst the sampled households in the study area. But the crops grown by the sampled households are subsistence in nature just meeting their food needs. Irrigation technology is another important aspect on which the adoption by the farmer depends. There are certain attributes of the cost, simplicity, profitability, immediate return 
and so forth. If the technology is unsuitable to the locality, the farmer will be unwilling to accept. On the other hand, if the technology is highly profitable and cost effective, it is likely to be adopted. To adopt environment friendly, economically viable, socially justifiable and locally satisfying type impact should be accepted.

The people inhabiting in the Chitwan are predominantly peasant farmers mainly cultivating paddy, maize, wheat, beans, lentils and mustard. The district is the major maize producing area, with an area under maize cultivation of 27,170 ha in the year 2003/2004. Maize is cultivated on irrigated / seasonal irrigated land in winter and spring, and on rain fed land in summer. Due to an easy road access, the produced maize can be easily distributed to other parts of the country. Due to an easy road access, maize produced can be without difficulty distributed to other parts of the country. It is abundantly spotted with clay lands, which are very good for growing paddy and wheat. Chitwan is famous for mustard growing and production of mustard oil. This reputation of the mustard in Chitwan is attributed to the predominant soil type silt, resulting from the flooding of the Narayani River and tributaries.

\section{Cropping Pattern}

Cropping pattern means the proportion of area under various crops at a point of time in a unit area or it indicated the yearly sequence and spatial arrangements of crops and follows in an area. Land resources being limited emphasis have to be placed for increasing production from unit area of land in a year. Cropping systems based on climate soil and water availability have to be evolved for realizing the potential production levels through efficient use of available resources. The cropping system should provide enough food for the family, fodder for cattle and generate sufficient cash income for domestic and cultivation expenses. This objective could be achieved by adopting intensive cropping. There are many types of cropping patterns. Growing of two or more crops simultaneously and intermingled on the same piece of land without row arrangements are called mixed cropping. This reduces risk and gives some insurance against failure of one of the crops. Intercropping is growing two or more crops simultaneously on the same field in a definite pattern. A few rows of one crop alternate with a few rows. Cropping pattern that involves the raising of crops, animals and/or trees. One of the important methods of intensive cropping, allowing the stubbles of the original crop to strike again after harvesting and to raise another crop. One crop variety grown alone in pure stand at normal density is also known as solid planting. This means repetitive growing of the same sole crop on the same land. One of the important methods of intensive cropping is allowing the stubbles of the original crop to strike again after harvesting and to raise another crop.

Cropping pattern determines the agronomic practices of a specific crop: to what extent it is grown, and in what seasons during the year. It is the cropping pattern of crops for a given piece of land. Methods of intensive cropping include multiple cropping and intercropping. Intensive cropping may pose some practical difficulties such as shorter turn-around time lapse for land preparation before the succeeding crop and labor shortage at peak agricultural activities. These problems can be overcome by making modification in the cropping techniques. Alteration in crop geometry may help to accommodate intercrops without losing the base crop production. There are different ways of growing crops to take maximum benefit is called cropping patterns. The growing of different crops on a piece of land in a pre-planned succession is known as crop rotation. The availability of moisture and irrigation facilities decides the choice. 
In self-governed PIS, the study reveals that the cropping pattern in spring season follows as: Spring Paddy-Summer Paddy-Oilseed and Dhaicha/Cowpea-Spring Paddy-Wheat-Summer Paddy in head reaches whereas before the system handover the major cropping pattern was Spring PaddySummer Paddy-Fallow (ICON 1995). Some of the farmers had included Spring Paddy in the crop sequence; however the area coverage under such pattern was very limited. The study also reveals that the cropping pattern in summer season follows as: Summer Paddy-Wheat-Maize, Summer PaddyFallow-Maize, Summer Paddy-Wheat/Pulses/Oilseed-Maize, Summer Paddy-Wheat/Oilseed-Maize, Summer Paddy-Wheat-Maize, Summer Paddy-Fallow-Fallow, Summer Paddy-Wheat/Pulses-Dhaicha, Summer Paddy-Fallow-Dhaicha/Maize, Summer Paddy-Wheat/Hybrid Maize-Maize, Summer PaddyFallow-Maize, Summer Paddy-Wheat-Fallow and Summer Paddy-Wheat/Cowpea-Maize whereas before the system handover the major cropping pattern was Spring paddy- Summer paddy-Fallow in spring season (ICON 1995). Some of the farmers had included spring paddy in the crop sequence; however the area coverage under such pattern was very limited. Whereas the cropping pattern in winter season follows as: Pulses- Summer Paddy-Oilseed/Pulses-Fallow.

In the case of tail reaches, now the cropping pattern is Dhaicha/Cowpea-Paddy-WheatSummer Paddy and Spring Paddy-Summer Paddy-Wheat in spring season whereas before the system handover to the farmers the cropping pattern was Summer Paddy-Fallow-Maize was in against the dominating cropping pattern of Chitwan district spring paddy-Wheat-Maize (ICON, 1995).From the study it was found that the cropping pattern in summer season was: Summer Paddy-Wheat/Pulses/ Oilseed-Maize, Summer Paddy-Fallow-Maize, Summer Paddy-Wheat/Pulses/Oilseed-Maize, Summer Paddy-Wheat/Oilseed-Maize, Summer Paddy-Wheat-Maize, Summer Paddy-Fallow-Maize, Summer Paddy-Dhaicha-Maize, and Summer Paddy-Wheat/Cowpea. While the cropping pattern in winter season was: Pulses-Summer Paddy-Oilseed/Pulses-Fallow.

In jointly-governed KIS, in spring season the cropping pattern is Spring Paddy-Pulses/ Oilseed-Maize, Fallow- Spring Paddy-Fallow and Dhaicha/Cowpea-Spring Paddy-Wheat-Summer Paddy in head reaches whereas before the system handover to the farmers the cropping pattern was Spring Paddy- Pulses-Fallow. According to some respondents, they were reluctant to grow especially spring paddy due to uncertainty of water for irrigation service where as some other respondents said that they had had to face various difficulties in harvesting and storing the paddy in rainy seasons such as expensive labor cost and also unavailability of laborers in time. As per the study, the cropping pattern in summer season follows: Summer Paddy-Wheat-Maize, Summer Paddy-Wheat/-Hybrid Maize-Maize, Summer Paddy-Fallow-Maize, Summer Paddy-Wheat/Pulses-Maize, and Summer Paddy-DhaichaMaize whereas the cropping pattern in winter season adopts: Pulses- Summer Paddy-Oilseed/PulsesFallow.

In the case of tail reaches of jointly-governed KIS now the cropping pattern is Dhaicha/ Cowpea-Spring Paddy-Wheat-Summer Paddy and it is the dominant pattern whereas before the system handover to the farmers the cropping pattern was Summer Paddy-Wheat-Fallow/Lentil against the dominating cropping pattern Summer Paddy-Wheat-Maize in Chitwan district (ICON 1995). In summer, Summer Paddy-Pulses/Oilseed-Maize/Dhaicha followed by Summer Paddy-Wheat-Maize, Summer Paddy- Fallow-Maize, Summer Paddy-Wheat/Pulses/Oilseed-Maize, Summer Paddy-Wheat/ Oilseed-Maize, Summer Paddy-Wheat/Pulses-Dhaicha, Summer Paddy-Dhaicha-Maize, Summer 
Paddy-Wheat/Maize Hybrid Maize, Summer Paddy-Fallow-Maize, Summer Paddy-Wheat-Fallow and Summer Paddy-Wheat/Cowpea-Maize. The study shows that the cropping pattern in winter season at present follows: Pulses-Summer Paddy-Oilseed/Pulses-Fallow.

Jointly-governed KIS areas have more or less similar cropping patterns to that of self-governed PIS areas, except that maize crop is grown relatively in larger area due to limited water in jointlygoverned KIS. In some areas, peas are also included in the crop rotation. In inference, crop like paddy, wheat, maize, lentil and mustard are commonly grown in both the systems.

The crop cannot wait for a turn of seven day rotation of water delivery service. The crops get excited by the time the turn for irrigation comes. Cultivation of spring paddy was done wherever irrigation is available thus building a cropping pattern of paddy- a winter crop of either wheat or lentil or mustard-early paddy. Some farmers skip winter crop and grow only two crops of paddy making a cropping pattern of Spring paddy- Summer paddy-Fallow was also found. Usually, maize grows as third crop in water deficit areas. In rare cases, the spring paddy was grown in the head reach depends mainly on the pumped ground water to meet the irrigation requirement throughout the crop cycle.

\section{Cropping Intensity}

The cropping intensity denotes to rising of a number of crops from the same field during one agricultural year. Thus, higher cropping intensity means that a higher proportion of the net shown area is being cropped more than once during one agricultural year. This also implies higher productivity per unit of arable land during one agricultural year (Table 1).

Table 1. Cropping Intensity by Irrigation Systems

\begin{tabular}{llllll}
\hline Cropping Intensity & \multicolumn{2}{l}{ Self-governed PIS } & \multicolumn{2}{l}{ Jointly-governed KIS } \\
& Head & Tail & Total & Head & Tail \\
$100-200$ & 0 & 0 & 0 & 20 & 20 \\
$200-300$ & 6 & 19 & 14 & 20 & 59 \\
$>300$ & 34 & 21 & 26 & 0 & 81 \\
Total & $\mathbf{4 0}$ & $\mathbf{4 0}$ & $\mathbf{4 0}$ & $\mathbf{4 0}$ & $\mathbf{1 6 0}$ \\
\hline
\end{tabular}

In the head reaches, 85 (34) percent respondents reported the 300 percent of the cropping intensity and 15 (6) percent respondents reported the 200-300 percent of the cropping intensity in selfgoverned PIS whereas in jointly-governed KIS, 65 (26) percent reported the 300 percent of the cropping intensity and 35 (14) percent respondents reported the 200-300 percent in the command areas. In the head reaches of both systems the cropping pattern was found higher than the Terai $(180.9 \%)$ and hill (only the 138.3\%). In tail reaches, 52.50 (21) percent respondents reported the 300 percent cropping intensity and 47.5 (19) percent respondents reported the 200-300 percent cropping intensity in selfgoverned PIS whereas in jointly-governed KIS, 50 (20) percent reported the 200-300 percent cropping intensity and 50 (20) percent respondents reported the 100-200 percent cropping intensity. In head reaches and tail reaches of the self-governed PIS, the cropping intensity was higher in comparison to "before the system handover", i.e., 200 percent in 1997 (ICON, 1997) but in jointly-governed KIS, the cropping intensity was higher only in head reaches. In the study areas, different crops were cultivated throughout the years. It depends on the water availability as well as the economics value of the crops 
except in some of the tail reaches of jointly-governed KIS. After handover of the systems, it was found changing pattern of cropping intensity where spring and summer paddy are in practice.

This change may not be directly attributed to irrigation. It was also due to the changes of time and increases the new demand from farming and other reaches communities. Specifically, the dry resistant crops are depending on the cost and benefit of production. It was apparent that the farmers at the head reaches were engaged more in farming during winter and spring seasons as compared to the tail reaches. It is noteworthy here to remember that the cultivation of maize is quite prevalent in the tail reaches. Although less water is available at the tail portion, the farmers grow the crops which required less water, thus contributing to higher crop intensity. Intensive cultivation had its positive association with percent of cropping intensity by produced from a unit of land to obtain desired yield from the irrigation services. New farming technologies are some of the key drivers of change in the cropping pattern, cropping intensity and crop productivity.

\section{Crop Productivity}

Water is generally limited or mismanaged in all irrigation schemes and water scarcities in the whole scheme or part of a scheme are among the major challenges constraining agricultural production. Hence, management of irrigation should aim at increasing the yield (production/value) per drop of water (Haileslassie, Peden, Gebreselassie, Amede, \& Descheemaeker, 2009, 33-40). Water productivity can be determined based on water delivery at different locations within irrigation system. For instance, water productivity determined at the headwork of the scheme, at the TC off take or at the FC levels of irrigation systems. It will be different due to unavoidable conveyance, distribution and on-farm application water losses (Dejen, 2014).

Table 2. Productivity in 2016 (MT per ha)

\begin{tabular}{lllllllll}
\hline Crop & \multicolumn{3}{l}{ Self-governed PIS } & \multicolumn{3}{c}{ Jointly-governed KIS } & Chitwan & National \\
& Head & Tail & Total & Head & Tail & Total & & \\
Spring Paddy & 3.0 & 3.0 & 3.0 & 3.0 & 2.5 & 2.75 & 3.9 & 3.1 \\
Summer Paddy & 3.00 & 3.00 & 3.0 & 3.00 & 2.99 & 3.0 & 3.9 & 3.1 \\
Wheat & 3.0 & 3.13 & 3.07 & 3.0 & 3.0 & 3.0 & 3.4 & 2.3 \\
Maize & 3.0 & 2.92 & 3.0 & 2.64 & 2.67 & 2.66 & 2.8 & 2.5 \\
Oilseeds & 0.77 & 0.79 & 0.79 & 0.79 & 0.8 & 0.8 & 0.8 & 0.6 \\
Pulses & 0.8 & 0.8 & 0.8 & 0.8 & 0.8 & 0.8 & 0.8 & 0.9 \\
\hline
\end{tabular}

(Field Study, 2016)

Variety of different crops cultivation in study area in year 2016 is presented in Table 3. Table 4, 5, 6, 7, 8 and 9 present the details of productivity of different crops.

Table 3. Variety in Cultivation in Study Area in Year 2016

\begin{tabular}{lllll}
\hline Crop & Self-governed PIS & Jointly-governed KIS & Chitwan & National \\
\hline Spring & Hardinath1 & Hardinath1 & Hardinath1 & Hardinath1 \\
Paddy & CH 45 & CH 45 & CH 45 & CH 45 \\
& Chaite 2 & Chaite 2 & Chaite 2 & Chaite 2 \\
& Chaite 4 & Chaite 4 & Chaite 4 & Chaite 4 \\
& Chaite 6 & Chaite 6 & Chaite 6 & Chaite 6
\end{tabular}




\begin{tabular}{lllll}
\hline Crop & Self-governed PIS & Jointly-governed KIS & Chitwan & National \\
\hline Summer & Sabitri & Sabitri & Sabitri & Sabitri \\
Paddy & Janaki & Janaki & Janaki & Janaki \\
& Radha 7 & Radha 7 & Radha 7 & Radha 7 \\
& Radhakrishna 9 & Radhakrishna 9 & Radhakrishna 9 & Radhakrishna 9 \\
& Mansuli & Mansuli & Mansuli & Mansuli \\
& Rampur masuli & Rampur masuli & Rampur masuli & Rampur masuli \\
& Loktantra & Loktantra & Loktantra & Loktantra \\
Wheat & RR 21 & RR 21 & RR 21 & RR 21 \\
& UP 262 & UP 262 & UP 262 & UP 262 \\
& Nepal 297 & Nepal 297 & Nepal 297 & Nepal 297 \\
& Brikuti & Brikuti & Brikuti & Brikuti \\
& Gautam & Gautam & Gautam & Gautam \\
& BL 1135 & BL 1135 & BL 1135 & BL 1135 \\
& NL 971 & NL 971 & NL 971 & NL 971 \\
Maize & Arun 2 & Arun 2 & Arun 2 & Arun 2 \\
& Rampur composite & Rampur composite & Rampur composite & Rampur composite \\
& Rampur 2 & Rampur 2 & Rampur 2 & Rampur 2 \\
Oilseeds & Yellow hybrid & Yellow hybrid & Yellow hybrid & Yellow hybrid \\
& Black hybrid & Black hybrid & Black hybrid & Black hybrid \\
& Sisir & Sisir & Sisir & Sisir \\
& Simal & Simal & Simal & Simal \\
& Sikhar & Sikhar & Sikhar & Sikhar \\
\hline & & & & (Field Study, 2016)
\end{tabular}

Spring paddy. Many people in Nepal devote their lives to cultivating paddy to survive and accounts for 35 percent of the cropped area in the country. It is also considered a prestigious crop in the society. Whether irrigated or rain-fed, paddy is the staple crop of the lowland. This is because paddy is the staple food commodity of the Nepalese people. Investment in irrigation, high-yield seeds, mechanization, and pricing incentives can easily boost paddy production and create jobs on the farm. Paddy requires a great deal of labor/ materials to create, and need large quantities of water for irrigation. Summer paddy is planted in 1,450,000 ha, while only 112,000 ha (7.7\%) grow spring paddy in Nepal because of the lack of reliable irrigation services (DoA, 2015).

Table 4. Spring Paddy Productivity (MT per ha)

\begin{tabular}{lllllll}
\hline Description & \multicolumn{2}{l}{ Self-governed PIS } & \multicolumn{4}{c}{ Jointly-governed KIS } \\
& Head & Tail & Total & Head & Tail & Total \\
No cultivation & 0 & 0 & 0 & 20 & 30 & 50 \\
1-2 MT per ha & 0 & 0 & 0 & 0 & 0 & 0 \\
2-3 MT per ha & 0 & 2 & 2 & 20 & 10 & 30 \\
> 3 MT per ha & 40 & 38 & 78 & 0 & 0 & 0 \\
Total & $\mathbf{4 0}$ & $\mathbf{4 0}$ & $\mathbf{8 0}$ & $\mathbf{4 0}$ & $\mathbf{4 0}$ & $\mathbf{8 0}$ \\
All total & $\mathbf{1 6 0}$ & & & & &
\end{tabular}

(Field Study, 2016) 
In head reaches, all the respondents reported more than 3 MT per ha productivity in selfgoverned PIS whereas in jointly-governed KIS, 50 (20) percent reported 3 MT per ha productivity. Similarly, in tail reaches 95 (38) percent respondents reported more than 3 MT per ha and 5 (2) percent 2-3 MT per ha in self-governed PIS whereas in jointly-governed KIS, 25 (10) percent reported 2-3 MT per ha productivity of spring paddy in the irrigation command areas. Due to the introduction of new cultivation techniques, the spring paddy production increased. The productivity of spring paddy was higher in self-governed PIS than the jointly-governed KIS in both head and tail reaches. The productivity was not so impressive in tail reaches in comparison of head reaches due to about 10-20 days delay of water supply in tail reaches in the same system too.

The productivity of the spring paddy in the self-governed PIS was more than 3 MT per ha which was equal of Chitwan and national productivity whereas in jointly-governed KIS, it was 2.75 MT per ha lower than the productivity of Chitwan (3.9 MT per ha) (DoA, 2015) and national average (3.1 MT per ha) (Agricultural Statistical Book, 2016). Its fluctuation in production was very common because of inadequate amount of water in winter and spring season, and water delivery was not in reliable time especially in winter and spring season as required of farmers. Despite the higher productivity of spring paddy, the cropped area is constrained by limiting water availability in spring season. Due to timely availability of irrigation in the head reaches of self-governed PIS, the productivity of spring paddy was found sound in comparison to jointly-governed KIS. However, spring paddy and other crops were found cultivated in very tiny area in spring and winter in both systems.

Summer paddy. During the 20th century, paddy field farming became the dominant form of growing paddy. It is to be understood that the crop yield is the output of quality seeds, optimum use of irrigation and timely farming practices. In some cases the crop yield has gone down due to less application of fertilizer and also due to excess soil moisture.

Table 5. Summer Paddy Productivity (MT per ha)

\begin{tabular}{lllllll}
\hline Description & \multicolumn{2}{l}{ Self-governed PIS } & \multicolumn{3}{l}{ Tointly-governed KIS } & \multirow{2}{*}{ Tail } \\
& Head & Tail & Total & Head & Total \\
No cultivation & 0 & 0 & 0 & 0 & 0 & 0 \\
1-2 MT per ha & 0 & 0 & 0 & 0 & 0 & 0 \\
2-3 MT per ha & 0 & 0 & 0 & 0 & 1 & 1 \\
>3 MT per ha & 40 & 40 & 80 & 40 & 39 & 79 \\
Total & $\mathbf{4 0}$ & $\mathbf{4 0}$ & $\mathbf{8 0}$ & $\mathbf{4 0}$ & $\mathbf{4 0}$ & $\mathbf{8 0}$ \\
All total & $\mathbf{1 6 0}$ & & & & & \\
\hline
\end{tabular}

(Field Study, 2016)

In head reaches, all the $(100 \%)$ respondents reported more than 3 MT per ha productivity in both systems. In tail reaches, 100 (40) percent respondents reported more than 3 MT per ha in selfgoverned PIS whereas in jointly-governed KIS, 97.5 (39) percent reported more than 3 MT and 2.5 (1) percent reported 2-3 MT per ha. In tail portion of the self-governed PIS (branch canal -6), there is mostly the clay mixed type of soil which has water retention capacity even in dries period. So, it is favorable for crop production eventually increasing the productivity.

The productivity of the self-governed PIS was almost equal with Chitwan (3.9 MT per ha) and which was higher in comparison to national average (3.1 MT per ha) whereas in jointly-governed KIS, is also found similar productivity (DoA, 2015). Due to timely availability of irrigation in the head reaches, the yields of summer paddy are considered normal. But in tail part, area under paddy is 
comparatively less and productivity is not impressive due to delay in water supply. It happens due to poor canal conditions in tail reaches than the head reaches in jointly-governed KIS.

Wheat. Wheat crop is a second important crop and its contribution to the agricultural sector is big in Tarai regions. Wheat is used basically to make bread, cake, chapatti, etc. Farmers also sell it if they have surplus production.

Table 6. Wheat Productivity (MT per ha)

\begin{tabular}{|c|c|c|c|c|c|c|}
\hline \multirow[t]{2}{*}{ Description } & \multicolumn{2}{|c|}{ Self-governed PIS } & \multirow[t]{2}{*}{ Total } & \multicolumn{2}{|c|}{ Jointly-governed KIS } & \multirow[t]{2}{*}{ Total } \\
\hline & Head & Tail & & Head & Tail & \\
\hline No cultivation & 16 & 18 & 34 & 16 & 23 & 39 \\
\hline 1-2 MT per ha & 0 & 0 & 0 & 0 & 0 & 0 \\
\hline 2-3 MT per ha & 0 & 0 & 0 & 0 & 0 & 0 \\
\hline$>3$ MT per ha & 24 & 22 & 46 & 24 & 17 & 41 \\
\hline Total & 40 & 40 & 80 & 40 & 40 & 80 \\
\hline All total & 160 & & & & & \\
\hline
\end{tabular}

(Field Study, 2016)

In head reaches, 60 (24) percent respondents reported more than 3 MT per ha productivity and 40 (16) percent reported no cultivation of wheat in self-governed PIS whereas in jointly-governed KIS, 55 (22) percent respondents reported more than 3 MT per ha productivity, 45 (18) percent reported no cultivation. Similarly, in tail reaches, 55 (22) percent respondents reported more than 3 MT per ha and 45 (18) percent no cultivation in the self-governed PIS whereas 42.5 (17) percent respondents reported more than 3 MT per ha, 57.5 (23) percent reported no cultivation.

The productivity of wheat in self-governed PIS was similar with Chitwan district (3.4 MT ha) and below than the national productivity (2.3 MT per ha) whereas in jointly-governed KIS is also similar productivity (DoA, 2015). Due to suitable and availability of irrigation in the head reaches, the yield of wheat is considered normal. Though, area under wheat is relatively less yield due to delay water supply in tail reaches (as chronic problem of scarce of water in winter and spring seasons).

Maize. Maize is the third most important food crop in the Terai. This is mainly grown for family consumption. In the Terai, maize is emerging as a commercial crop for processing into glucose, breakfast, animal feed and corn oil. The demand for maize is expected to grow by 4 percent per year over the next 20 years as a result of increased demand for food in the hills and in the Terai region. Maize being the second most important staple food commodity in Nepalese agriculture and economy covers nearly 80 percent of the hill area. It is grown under rain-fed conditions and mostly on marginal land. Maize is commonly grown with millet, mostly in a relay system. Other important cropping systems are maize associated with soybeans, legumes, radish, potatoes and upland paddy. The Terai region, which has high potential for maize, accounts for 20 percent of the maize area and this, is increasing, particularly due to accessible markets. 
Table 7. Maize Productivity (MT per ha)

\begin{tabular}{lllllll}
\hline Description & \multicolumn{2}{l}{ Self-governed PIS } & \multicolumn{3}{c}{ Jointly-governed KIS } \\
& Head & Tail & Total & Head & Tail & Total \\
No cultivation & 18 & 14 & 32 & 20 & 12 & 32 \\
1-2 MT per ha & 0 & 0 & 0 & 0 & 0 & 0 \\
2-3 MT per ha & 0 & 4 & 4 & 4 & 18 & 22 \\
>3 MT per ha & 22 & 22 & 44 & 16 & 10 & 26 \\
Total & $\mathbf{4 0}$ & $\mathbf{4 0}$ & $\mathbf{8 0}$ & $\mathbf{4 0}$ & $\mathbf{4 0}$ & $\mathbf{8 0}$ \\
All total & $\mathbf{1 6 0}$ & & & & &
\end{tabular}

(Field Study, 2016)

In head reaches 55 (22) percent respondents reported more than 3 MT per ha productivity and 45 (18) percent respondents reported no cultivation of maize in self-governed PIS whereas in jointlygoverned KIS, 55 (22) percent respondents reported more than 3 MT per ha, 10 (4) percent respondents reported more than 2-3 MT per ha and 35 (14) percent respondents reported no cultivation. Similarly, in tail reaches 55 (22) percent respondents reported more than 3 MT per ha productivity, 10 (4) percent respondents reported that 2-3 MT per ha and 35 (14) percent were no cultivation in the self-governed PIS whereas in jointly-governed KIS, 25 (10) percent respondents reported more than 3 MT per ha, 45 (18) percent reported 2-3 MT per ha and the remaining 30 (12) percent reported no cultivation. In self-governed PIS, the maize productivity (2.8 MT per ha) was high the Chitwan district (2.5 MT per ha) (DoA, 2015) whereas in jointly-governed KIS is below than Chitwan. The key informants were revealed the variation in the production of maize in two systems is owing to the access of water and types of the soils causing. In tail portion of both systems the soil is mostly clay mixed, where reducing the aeration in root zone eventually declining the crop productivity.

Oil seeds. Oilseed production had shown moderate growth since 1980. Oilseed crops: rapeseed, mustard, tori, groundnut, sesame and sunflower have potential in the country particularly in Tarai regions. They are both oil producing and income generating cash crops. National mustard oil demand is in deficit by an estimated 27,000 MT. The local crop has higher oil recovery rates than the imported one. Only mustard seeds has been grown in the study year.

Table 8. Productivity of Oil Seeds (MT per ha)

\begin{tabular}{lllllll}
\hline Description & \multicolumn{2}{l}{ Self-governed PIS } & \multicolumn{3}{l}{ Jointly-governed KIS } \\
& Head & Tail & Total & Head & Tail & Total \\
No cultivation & 1 & 14 & 15 & 20 & 38 & 58 \\
0.4-0.6 MT per ha & 0.0 & 0.0 & 0.0 & 0.0 & 0.0 & 0.0 \\
0.6-0.8 MT per ha & 12 & 0.0 & 12 & 2 & 0.0 & 2 \\
>0.8 MT per ha & 27 & 26 & 53 & 18 & 2 & 20 \\
Total & $\mathbf{4 0}$ & $\mathbf{4 0}$ & $\mathbf{8 0}$ & $\mathbf{4 0}$ & $\mathbf{4 0}$ & $\mathbf{8 0}$ \\
All total & $\mathbf{1 6 0}$ & & & & & \\
\hline
\end{tabular}

(Field Study, 2016)

In head reaches, 67.5 (27) percent respondent reported more than $0.8 \mathrm{MT}$ per ha productivity; 30 (12) percent responded reported 0.6-0.8 MT per ha and 2.5 (1) percent respondent reported no cultivated oil seeds in self-governed PIS whereas in jointly-governed KIS only 45 (18) percent respondent reported more than 0.8 MT per ha productivity, 5 (2) percent responded reported 0.6-0.8 MT per ha and 50 (20) percent responded reported about no cultivation. Similarly, in tail reaches 65 (26) percent respondents reported more than 0.8 MT per ha productivity and 35 (14) percent respondents reported no cultivation 
in self-governed PIS whereas in jointly-governed KIS, 5 (2) percent respondents reported more than $0.8 \mathrm{MT}$ per ha and 95 (38) percent reported about no cultivation. The average productivity of oilseeds 0.7 MT per ha was below in self-governed PIS than Chitwan district (0.8 MT per ha) and higher than the national productivity (0.6 MT per ha) (DoA, 2015) whereas in the jointly-governed KIS, $0.8 \mathrm{MT}$ per ha productivity which was below than the Chitwan and higher than the national productivity. As reported by the key informants, the mustard showed diminishing crop productivity in the last few years in head reaches of jointly-governed KIS. As reported by key informants the crop area and yield both are decreasing in both systems.

Pulses. Under rain-fed conditions, pulses can play an important role in crop diversification. Lentil is the most important pulse crop in the Terai region. Lentils and soybean commodities are highly demanded and farmers therefore can sell these items easily. Soybean accounted for about 7 percent of the area and 7 percent of the production of legumes in Nepal. Intercropping with maize gives good yields. The lentil's export markets are India, Bangladesh, Pakistan and Sri Lanka. Nepalese demand is 122,000 tons, which exceeds the supply of 113,520 tons per annum. In the case of grain legumes, there is a big yield gap between research stations and farmers' fields. This may indicate that the generated technology still needs to be verified in farmers' fields and conditions.

Table 9. Productivity of Pulses (MT per ha)

\begin{tabular}{lllllll}
\hline Description & \multicolumn{2}{l}{ Self-governed PIS } & \multicolumn{3}{l}{ Jointly-governed KIS } \\
& Head & Tail & Total & Head & Tail & Total \\
No cultivation & 12 & 24 & 36 & 18 & 24 & 42 \\
0.4-0.6 MT per ha & 0.0 & 0.0 & 0.0 & 0.0 & 0.0 & 0.0 \\
0.6-0.8 MT per ha & 0.0 & 0.0 & 0.0 & 0.0 & 0.0 & 16 \\
$>0.8$ MT per ha & 28 & 16 & 44 & 22 & 16 & 22 \\
Total & $\mathbf{4 0}$ & $\mathbf{4 0}$ & $\mathbf{8 0}$ & $\mathbf{4 0}$ & $\mathbf{4 0}$ & $\mathbf{8 0}$ \\
All total & $\mathbf{1 6 0}$ & & & & & \\
\hline
\end{tabular}

In head reaches, 70 (28) percent responded reported more than 0.8 MT per ha productivity and 30 (12) percent responded reported about no cultivation in self-governed PIS whereas in jointlygoverned KIS, only 55 (22) percent responded reported more than 0.8 MT per ha and 45 (18) percent responded reported about no cultivation. Similarly, in tail reaches, 40 (16) percent responded reported more than 0.8 MT per ha productivity and 60 (24) percent responded reported about no cultivation in self-governed PIS whereas in jointly-governed KIS, only 40 (16) percent responded reported more than 0.8 MT per ha and 60 (24) percent responded reported about no cultivation. The productivity of pulses was 0.8 in self-governed PIS which is equal to Chitwan district ( 0.8 MT per ha) and below than the national productivity (0.9 MT per ha) (DoA, 2015) whereas in the jointly-governed KIS, it was also equal to Chitwan and national productivity. As reported by the key informants, the productivity of pulses is going diminishing in the last few years in head reaches of jointly-governed KIS. The reasons for decreasing crop yield were due to excess moisture in the soil.

Nepalese Journal of Development and Rural Studies, Volume 15, 2018 


\section{Conclusion}

It is concluded that Chitwan district has experienced rapid agriculture development growth over the last sixty years after a paradigm of resettlement policies. The crops cultivation more than one time in a year has its positive relationship with cropping intensity and vice versa in the study area. Hence, households need to get up and should be encouraged towards year round irrigation that helps produce different types of crops in different seasons and ultimately back up in cropping intensity as well as productivity. In head and tail reaches of the self-governed PIS was able to get adequate water service and was able to product more in comparison to the head and tail reaches of the jointly-governed KIS. The productivity was found similar with the productivity of Chitwan district and national. The crop production is fluctuated widely as a result of amount of water available as well as weather conditions. Despite the higher yield of spring paddy, the cropped area is constrained due to limit water availability in spring season. In this regards, the study seek out, the way of fullfledged governance and sustainability of irrigation systems by combining the attributes of bio-physical condition, community and institutional rules, and water adequate, fairness and reliability, and physical, financial and institutional sustainability.

\section{References}

APROSC \& John Mellor Associates, Inc. (1995). Nepal agriculture perspective plan. Kathmandu: $\mathrm{NPC}, \mathrm{HMG} / \mathrm{N}$.

APROSC \& John Mellor Associates, Inc. (1998). Agriculture program research and service centre. Kathmandu: Government of Nepal, Ministry of Agriculture and Irrigation.

Department of Irrigation (DoI). (1997). Institutional development support component report. Lalitpur: Government of Nepal.

Department of Irrigation (DoI). (2002). Annual progress report. Lalitpur: Government of Nepal.

Department of Irrigation (DoI). (2008). Irrigation national workshop. In S. Sijapati \& K. R Sharma (Eds.), irrigation in the changing context: From concepts to actions (231-261). doi/NEA/ INPIM-Nepal/IWMI-Nepal.

Department of Irrigation (DoI). (2016). Irrigation handbook. Lalitpur: Department of Irrigation, Nepal.

ICON (1997). Baseline study of Khageri irrigation system. Kathmandu: Government of Nepal. 